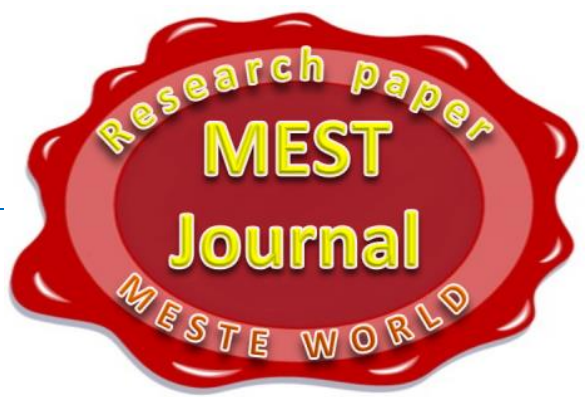

\title{
NEW METHODS OF SOFT COMPUTING IN REGIONAL DEVELOPMENT STRATEGY FORMATION
}

\author{
Yaroslav Vyklyuk \\ Bukovinian University, Chernivtsi, Ukraine \\ Valeriy Yevdokymenko \\ Bukovyna State University of Finance and Economics, Chernivtsi, Ukraine
}

\author{
() MESTE NGO \\ JEL category: C51, C52, R58
}

\begin{abstract}
An urgent necessity in socio-economic regional development strategy specification is being substantiated for the purpose of reconstructing and adjusting the TEA (Types of Economic Activity) structure, which is able to speed up the development of GRP (Gross Regional Product), GS (Gross Surplus) per person and steadily grade current interregional differentiation and asymmetry. To reach the target a special algorithm for Soft Computing has been created. On the example of the selected region it was proved that the present economic system is not self-organized and it requires an efficient public management. If the regional management strategy is not optimally chosen then in the system some uncontrolled fluctuations can be observed, that may lead to an economic crisis and the "collapse" of the economy system. Mathematical models of optimization of strategies building of 3 types have been constructed and their effectiveness has been quantitatively researched. It is proved, that the dynamic management strategy with the maximizing of the objective function at the end of the period under investigation, turned out to be the most effective. It is established that public administration which is based on a scientifically grounded quantitative approach, using advanced mathematical models of Soft Computing, allows building a strong economic foundation, which will be the basis for a further rapid growth of the regional economy.
\end{abstract}

Keywords: soft computing, economic modelling, neural networks, regional development strategy

\section{INTRODUCTION}

The issues of asymmetry and unequal regional development, striking differentiation are under consideration in numerous publications on the subject. New approaches to the development of

Address of the corresponding author: Yaroslav Vyklyuk

莑: vyklyuk@ukr.net reproducing different structural types in the framework of the intensive growth and interregional leveling of added value creation per capita are not founded, a driving force algorithm, which might be oriented on fulfilling the task as a stable way practice, haven't been proposed yet.

In general terms the task lies in the following: to formulate an algorithm of defining envisaging the constituents and dynamics of tempo and 
proportions meeting the demands of the relevant regional conditions of various forms of economic activities which provide a necessary scale of the market actors' participation in the reproduction process to increase the output of the added value per capita. It can also be proved that the deviation of the predicted values from the analogous values elaborated by the classical trend models can be an important criterion of the regional development efficiency evaluation which was already calculated for the regional development strategy by the classical trend models.
It is suggested to consider the referred issues and make calculations on the data of Chernivtsi region of Ukraine.

\section{THE PROGNOSTICATION OF THE REGIONAL DEVELOPMENT ON THE BASIS OF TRENDS MODELS}

Let's arrange the economic activities according to two criteria: (1) the proportion of value added in the production of economic activity, and (2) the ratio of the contribution of economic activity in the GVA of the region (table 1).

Table 1 The basic economic activities of Chernivtsy region

\begin{tabular}{|l|l|l|}
\hline No. & $\begin{array}{l}\text { The share of value added in production } \\
\text { of economic activity kinds (EAK) }\end{array}$ & $\begin{array}{l}\text { The share of EAK contribution to GVA of } \\
\text { the area }\end{array}$ \\
\hline 1 & Financing activities (77.1\%) & Agriculture, hunting and forestry (18.7\%) \\
\hline 2 & Education (71.0\%) & $\begin{array}{l}\text { Trade, repair of motor vehicles, household } \\
\text { goods, and items of personal use (16.8\%) }\end{array}$ \\
\hline 3 & Public administration (67.9\%) & Education (11.1\%) \\
\hline 4 & $\begin{array}{l}\text { Trade, repair of motor vehicles, household } \\
\text { goods, and items of personal use (66.9\%) }\end{array}$ & Public administration (9.7\%) \\
\hline 5 & Health care and social assistance (66.4\%) & $\begin{array}{l}\text { Transport and communications activities } \\
(8.7 \%)\end{array}$ \\
\hline 6 & $\begin{array}{l}\text { Provision of collective and individual service; } \\
\text { activities in the field of culture and sport; } \\
\text { activities of households; activities of extra- } \\
\text { territory organizations (62.5\%) }\end{array}$ & Manufacturing (8.4\%) \\
\hline 7 & $\begin{array}{l}\text { Transport, storage and communication } \\
\text { (55.5\%) }\end{array}$ & Health care and social assistance (5.5\%) \\
\hline 8 & $\begin{array}{l}\text { Real estate, leasing, engineering and } \\
\text { providing services to businessmen (55.3\%) }\end{array}$ & $\begin{array}{l}\text { Real estate, leasing, engineering and } \\
\text { providing services to businessmen (5.4\%) }\end{array}$ \\
\hline 9 & Mining (46.7\%) & Construction (5.3\%) \\
\hline 10 & Agriculture, hunting and forestry (44.8\%) & Financial activities (3.4\%) \\
\hline
\end{tabular}

Source: Calculated by the authors on the basis of data from the State Statistics Service of Ukraine.

The proposed ranking actualizes the issue of the rates and proportions which should be used to develop economic activities in the region to maximize the production of GVA.

Thus, we come to the conclusion that to model a modified strategy of the EAK development we must find a similar form of the functional dependence of the total value added of GVA upon EAK. It is logical to select the most important economic activities to achieve the objective. On the basis of ranking, nine most influential EAK have been selected (the Table 2).
The trend model involves the calculation of predictive values, provided that the system will evolve according to well-established trends. During the calculation the 25 classical trend functions were analyzed. The best agreement with experimental data was shown by the linear and quadratic function:

$$
\begin{aligned}
& \mathrm{GVA}_{\text {line }}=-1637238,2+818,69091 \cdot \mathrm{Y} \\
& G V A_{\text {quad }}=-191176060-191466,221 \cdot Y+ \\
& 47,939394 \cdot Y^{2}
\end{aligned}
$$

where $Y-$ is a year. 
Vyklyuk Y. Soft computing in development strategy formation

MEST Journal Vol. 2 No. 2 pp. 274-284

According to created trend models in 5 years in prognostication and $16,353 \mathrm{mln}$ UAH if the 2015 we can expect the next size of added values: growing has quadratic trend. We will consider $12,424 \mathrm{mln}$ UAH according to the linear these values as patterns (figure 1)

Table 2. Dynamics of gross value added according to the types of economic activities (At current prices in $\mathrm{mln}$. UAH)

\begin{tabular}{|c|l|c|c|c|c|c|c|c|c|c|c|}
\hline № & \multicolumn{1}{|c|}{$\begin{array}{c}\text { Types of economic } \\
\text { activities }\end{array}$} & $\mathbf{2 0 0 1}$ & $\mathbf{2 0 0 2}$ & $\mathbf{2 0 0 3}$ & $\mathbf{2 0 0 4}$ & $\mathbf{2 0 0 5}$ & $\mathbf{2 0 0 6}$ & $\mathbf{2 0 0 7}$ & $\mathbf{2 0 0 8}$ & $\mathbf{2 0 0 9}$ & $\mathbf{2 0 1 0}$ \\
\hline$G V A$ & Total & $\mathbf{1 7 4 0}$ & $\mathbf{2 0 0 2}$ & $\mathbf{2 3 8 2}$ & $\mathbf{2 8 8 8}$ & $\mathbf{3 6 6 5}$ & $\mathbf{4 4 0 1}$ & $\mathbf{5 7 9 2}$ & $\mathbf{7 5 8 6}$ & $\mathbf{7 3 9 1}$ & $\mathbf{8 6 1 7}$ \\
\hline$\left(x_{1}\right)$ & $\begin{array}{l}\text { Agriculture, hunting and } \\
\text { forestry }\end{array}$ & 575 & 600 & 581 & 734 & 894 & 916 & 1194 & 1503 & 1488 & 1800 \\
\hline$\left(x_{2}\right)$ & Manufacturing & 230 & 248 & 321 & 337 & 470 & 604 & 860 & 973 & 770 & 808 \\
\hline$\left(x_{3}\right)$ & Construction & 70 & 90 & 131 & 171 & 233 & 326 & 464 & 627 & 443 & 513 \\
\hline$\left(x_{4}\right)$ & $\begin{array}{l}\text { Trade, repair of motor } \\
\text { vehicles, household goods } \\
\text { and items of personal use }\end{array}$ & 311 & 349 & 467 & 593 & 708 & 804 & 1127 & 1433 & 1383 & 1620 \\
\hline$\left(x_{5}\right)$ & $\begin{array}{l}\text { Transport and } \\
\text { lommunication }\end{array}$ & 145 & 206 & 264 & 311 & 356 & 432 & 472 & 694 & 721 & 834 \\
\hline$\left(x_{6}\right)$ & $\begin{array}{l}\text { Real estate, leasing, } \\
\text { engineering, and providing } \\
\text { services to businessmen }\end{array}$ & 98 & 114 & 123 & 142 & 174 & 258 & 337 & 447 & 449 & 515 \\
\hline$\left(x_{7}\right)$ & Public administration & 90 & 119 & 138 & 176 & 285 & 379 & 483 & 773 & 787 & 932 \\
\hline$\left(x_{8}\right)$ & Education & 149 & 188 & 245 & 290 & 375 & 466 & 583 & 788 & 925 & 1070 \\
\hline$\left(x_{9}\right)$ & $\begin{array}{l}\text { Healthcare and social } \\
\text { assistance }\end{array}$ & 72 & 88 & 112 & 134 & 170 & 216 & 272 & 348 & 425 & 525 \\
\hline
\end{tabular}

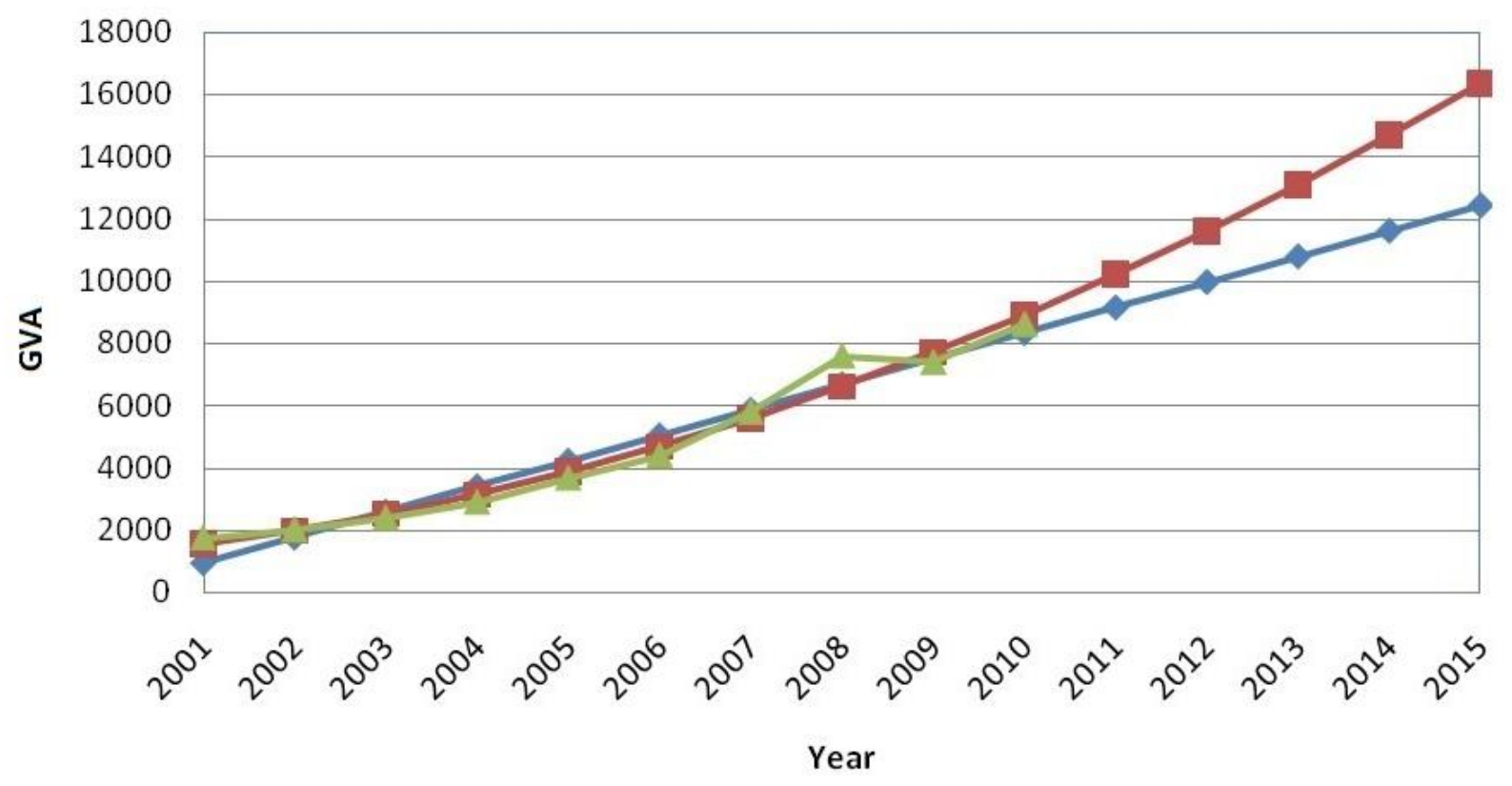

$\leadsto$ Linear trend $\rightarrow$ Quadratic trend $\rightarrow$ Experimental data

Fig. 1 The dynamics of the Gross Value Added 

MEST Journal Vol. 2 No. 2 pp. 274-284

The problem of the construction of region development strategy based on analytical form of functional dependences of the gross value added on their components means that there are no data about factors which affect $x_{i}$ components. The classical prognostication method means it is necessary to build the trend model for each $x_{i}$.

Table 3 The results of the correlation analyses between components of the gross value added

\begin{tabular}{|l|c|c|c|c|c|c|c|c|c|}
\hline & $x_{1}$ & $x_{2}$ & $x_{3}$ & $x_{4}$ & $x_{5}$ & $x_{6}$ & $x_{7}$ & $x_{8}$ & $x_{9}$ \\
\hline$x_{1}$ & 1.00 & & & & & & & & \\
\hline$x_{2}$ & 0.90 & 1.00 & & & & & & & \\
\hline$x_{3}$ & 0.93 & 0.99 & 1.00 & & & & & & \\
\hline$x_{4}$ & 0.99 & 0.94 & 0.96 & 1.00 & & & & & \\
\hline$x_{5}$ & 0.98 & 0.89 & 0.92 & 0.99 & 1.00 & & & & \\
\hline$x_{6}$ & 0.99 & 0.93 & 0.95 & 0.99 & 0.98 & 1.00 & & & \\
\hline$x_{7}$ & 0.99 & 0.90 & 0.93 & 0.99 & 0.99 & 0.99 & 1.00 & & \\
\hline$x_{8}$ & 0.99 & 0.88 & 0.90 & 0.98 & 0.99 & 0.99 & 0.99 & 1.00 & \\
\hline$x_{9}$ & 0.99 & 0.85 & 0.88 & 0.97 & 0.99 & 0.98 & 0.99 & 1.00 & 1.00 \\
\hline
\end{tabular}

Next, on the prognostication values of $x_{i}$, prognostication values of the gross value added can be determined. Our calculation showed the similar results can be achieved. The disadvantage of this approach is that it is unusable to realization of the sensitivity analyses and therefore it is unable to use for optimization of region development strategy. The correlation analysis was held for investigation of $x_{i}$ components interplay (table 3).

As it can be seen from the table the close correlation relationship between all $x_{i}$ components is observed. Moreover the minimum value of correlation coefficient is equal to 0.85 . According to the classical math theory the factor analysis must be carried through for decreasing of model components number (Katsikatsou, Moustaki, Yang-Wallentin, \& Joreskog, 2012). As a result of this analysis the new factors are obtained. These factors are linear dependent on $x_{i}$ components. Unfortunately, the semantic content of new factors is lost. This makes further analysis and interpretation of results more difficult.

\section{THE DEVELOPMENT OF ECONO- MIC MATHEMATICAL METHOD FOR PROGNOSTICATION OF THE REGION STRATEGY DEVELOP- MENT ON THE BASIS OF HOPFIELD NEURAL NETWORK}

A new math method for optimization of the region strategy development in a close relationship between economic activities was proposed. It consists of the following steps:

Step 1. Development of the regression models.

On this step it is necessary to carry through the regression analysis. It will enable to determine the functional dependences between $x_{i}$ factors and conduct the sensitivity analysis. The nine dependencies were obtained after that:

$$
\begin{aligned}
& x_{1}=-0,02 \cdot x_{2}-0,45 \cdot x_{3}+1,09 \cdot x_{4}-0,78 \cdot x_{5}-1,21 \cdot x_{6}+1,93 \cdot x_{7}-1,88 \cdot x_{8}+2,55 \cdot x_{9}+440 \\
& x_{2}=-0,002 \cdot x_{1}+2,67 \cdot x_{3}-0,55 \cdot x_{4}-1,40 \cdot x_{5}-1,04 \cdot x_{6}-0,78 \cdot x_{7}+2,70 \cdot x_{8}-0,72 \cdot x_{9}+247 \\
& x_{3}=-0,006 \cdot x_{1}+0,36 \cdot x_{2}+0,22 \cdot x_{4}+0,51 \cdot x_{5}+0,40 \cdot x_{6}+0,30 \cdot x_{7}-1,02 \cdot x_{8}+0,27 \cdot x_{9}-89 \\
& x_{4}=0,23 \cdot x_{1}-1,13 \cdot x_{2}+3,36 \cdot x_{3}-1,47 \cdot x_{5}-1,11 \cdot x_{6}-1,33 \cdot x_{7}+3,67 \cdot x_{8}-1,29 \cdot x_{9}+199 \\
& x_{5}=-0,04 \cdot x_{1}-0,66 \cdot x_{2}+1,78 \cdot x_{3}-0,33 \cdot x_{4}-0,81 \cdot x_{6}-0,43 \cdot x_{7}+1,77 \cdot x_{8}-0,39 \cdot x_{9}+186 \\
& x_{6}=-0,07 \cdot x_{1}-0,59 \cdot x_{2}+1,68 \cdot x_{3}-0,31 \cdot x_{4}-0,97 \cdot x_{5}-0,27 \cdot x_{7}+1,59 \cdot x_{8}-0,17 \cdot x_{9}+196
\end{aligned}
$$


$x_{7}=0,18 \cdot x_{1}-0,73 \cdot x_{2}+2,04 \cdot x_{3}-0,61 \cdot x_{4}-0,85 \cdot x_{5}-0,45 \cdot x_{6}+2,36 \cdot x_{8}-1,05 \cdot x_{9}+91$

$x_{8}=-0,02 \cdot x_{1}+0,34 \cdot x_{2}-0,93 \cdot x_{3}+0,22 \cdot x_{4}+0,47 \cdot x_{5}+0,35 \cdot x_{6}+0,31 \cdot x_{7}+0,33 \cdot x_{9}-75$

$x_{9}=0,15 \cdot x_{1}-0,42 \cdot x_{2}+1,15 \cdot x_{3}-0,37 \cdot x_{4}-0,48 \cdot x_{5}-0,17 \cdot x_{6}-0,65 \cdot x_{7}+1,60 \cdot x_{8}+31$

Step 2. Sensitivity analysis.

On this step the analyses "What-if" is conducted. To do this the values of $x_{i}$ factors were fixed on 2010 year and after that these factors have been changing alternately on $10 \%$. It allowed

Table 4. The sensitivity analysis of the regression models after the change of input parameters on $10 \%$

\begin{tabular}{|c|c|c|c|c|c|c|c|c|c|c|}
\hline \multirow{2}{*}{\multicolumn{2}{|c|}{ Output parameters }} & \multicolumn{9}{|c|}{ Input parameters } \\
\hline & & $x_{1}$ & $x_{2}$ & $x_{3}$ & $x_{4}$ & $x_{5}$ & $x_{6}$ & $x_{7}$ & $x_{8}$ & $x_{9}$ \\
\hline \multirow{2}{*}{$x_{1}$} & mln. UAH & & 1802 & 1780 & 1979 & 1738 & 1741 & 1983 & 1603 & 1937 \\
\hline & increment & & $0 \%$ & $-1 \%$ & $10 \%$ & $-4 \%$ & $-3 \%$ & $10 \%$ & $-11 \%$ & $7 \%$ \\
\hline \multirow{2}{*}{$x_{2}$} & mln. UAH & 807 & & 944 & 718 & 691 & 754 & 735 & 1096 & 769 \\
\hline & increment & $0 \%$ & & $17 \%$ & $-11 \%$ & $-14 \%$ & $-7 \%$ & $-9 \%$ & $36 \%$ & $-5 \%$ \\
\hline \multirow{2}{*}{$x_{3}$} & mln. UAH & 512 & 543 & & 549 & 556 & 534 & 541 & 405 & 527 \\
\hline & increment & $0 \%$ & $6 \%$ & & $7 \%$ & $8 \%$ & $4 \%$ & $5 \%$ & $-21 \%$ & $3 \%$ \\
\hline \multirow{2}{*}{$x_{4}$} & mln. UAH & 1659 & 1526 & 1789 & & 1495 & 1560 & 1493 & 2011 & 1550 \\
\hline & increment & $3 \%$ & $-6 \%$ & $11 \%$ & & $-8 \%$ & $-4 \%$ & $-8 \%$ & $24 \%$ & $-4 \%$ \\
\hline \multirow{2}{*}{$x_{5}$} & mln. UAH & 827 & 780 & 925 & 779 & & 792 & 793 & 1023 & 813 \\
\hline & increment & $-1 \%$ & $-6 \%$ & $11 \%$ & $-7 \%$ & & $-5 \%$ & $-5 \%$ & $23 \%$ & $-2 \%$ \\
\hline \multirow{2}{*}{$x_{6}$} & mln. UAH & 502 & 467 & 601 & 465 & 434 & & 490 & 685 & 506 \\
\hline & increment & $-2 \%$ & $-9 \%$ & $17 \%$ & $-10 \%$ & $-16 \%$ & & $-5 \%$ & $33 \%$ & $-2 \%$ \\
\hline \multirow{2}{*}{$x_{7}$} & mln. UAH & 963 & 871 & 1035 & 831 & 859 & 907 & & 1183 & 875 \\
\hline & increment & $4 \%$ & $-6 \%$ & $11 \%$ & $-11 \%$ & $-8 \%$ & $-2 \%$ & & $27 \%$ & $-6 \%$ \\
\hline \multirow{2}{*}{$x_{8}$} & mln. UAH & 1067 & 1098 & 1023 & 1107 & 1110 & 1089 & 1100 & & 1088 \\
\hline & increment & $0 \%$ & $3 \%$ & $-4 \%$ & $3 \%$ & $4 \%$ & $2 \%$ & $3 \%$ & & $2 \%$ \\
\hline \multirow{2}{*}{$x_{9}$} & mln. UAH & 548 & 486 & 579 & 461 & 480 & 511 & 459 & 687 & \\
\hline & increment & $5 \%$ & $-7 \%$ & $11 \%$ & $-11 \%$ & $-8 \%$ & $-2 \%$ & $-12 \%$ & $32 \%$ & \\
\hline
\end{tabular}

As it can be seen on the table, the processing industry does not affect agriculture, while the increasing of the added value of trade or public administration on $10 \%$ will lead to corresponding increase of added value in the agriculture. In contrast, the education development (the added value will increase on 10\%) will lead to decreasing of added value in agriculture on $11 \%$.

It means that the analysis of each coefficient of the table is very capacious and the grouping of economic activities, existing in statistics, makes it investigating the change of output values (VGA) for both absolute and relative terms. Such analysis allows building the strategy of development for one time period, in our case for one year. The results of this analysis are presented in the Table 4. 
(fig. 2.). As it can be seen from the figure, solid lines show the influence of one kind of neurons to others. Dashed lines indicate the lack of communication between neurons. The feedbacks transmit signals from the second neuron layer to the first one unchanged. On the first step the values of gross value added for the last year (2010) are submitted on the first neuron layer. The next equation is used for calculation of the values of the second neuron layers, and accordingly the values of the first neuron layer for the second iteration step:

$X^{i+1}=X^{i} \cdot W^{T}+B^{T}$

where:

- $\quad X^{i}-$ is a vector of the first neuron layer for $i$-th iteration,

- $W$ and $B$ - the linear regressions coefficients, that link types of economic activities.

The next values of matrix elements were obtained accordingly to (3-11) and the Table 2:

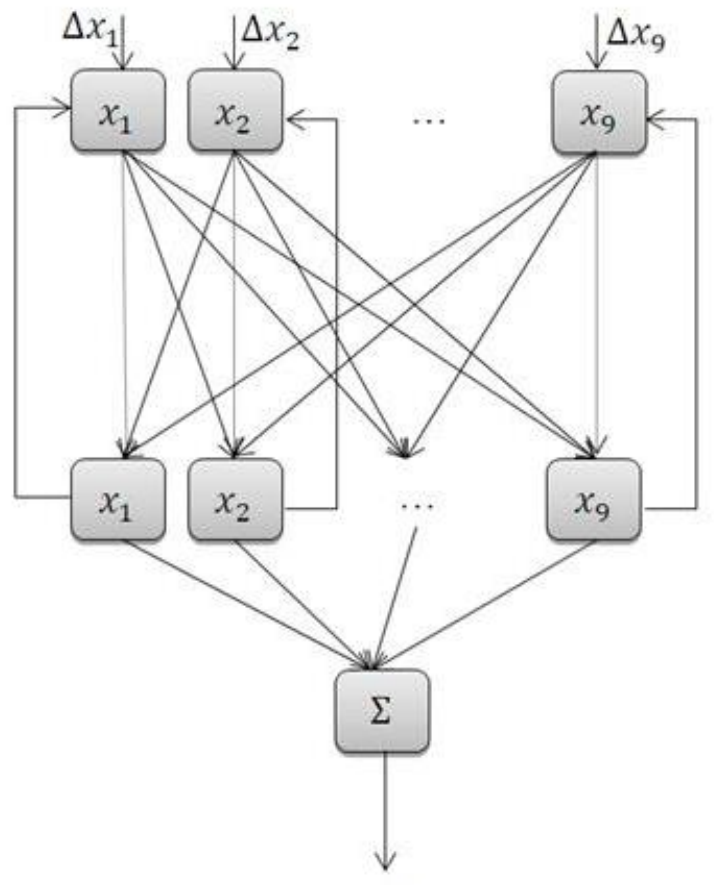

GVA

Fig.2 Hopfield neural network for gross value added calculation

$W=\mid \begin{array}{ccccccccc}0 & -0,02 & -0,45 & 1,09 & -0,78 & -1,21 & 1,93 & -1,88 & 2,55 \\ 0,00 & 0 & 2,67 & -0,55 & -1,40 & -1,04 & -0,78 & 2,70 & -0,72 \\ -0,01 & 0,36 & 0 & 0,22 & 0,51 & 0,40 & 0,30 & -1,02 & 0,27 \\ 0,23 & -1,13 & 3,34 & 0 & -1,47 & -1,11 & -1,33 & 3,67 & -1,29 \\ -0,04 & -0,66 & 1,78 & -0,33 & 0 & -0,81 & -0,43 & 1,77 & -0,39 \\ -0,07 & -0,59 & 1,68 & -0,31 & -0,97 & 0 & -0,27 & 1,59 & -0,17 \\ 0,18 & -0,73 & 2,04 & -0,61 & -0,85 & -0,45 & 0 & 2,36 & -1,05 \\ -0,02 & 0,34 & -0,93 & 0,22 & 0,47 & 0,35 & 0,31 & 0 & 0,33 \\ 0,15 & -0,43 & 1,15 & -0,37 & -0,48 & -0,17 & -0,65 & 1,56 & 0\end{array}$

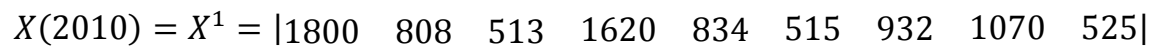

Table 4. The change of the GVA values according to iterations.

\begin{tabular}{|l|c|c|c|c|c|c|}
\hline Iteration & 1 & 2 & 3 & 4 & 5 & 6 \\
\hline GVA & 8617 & 8611 & 8638 & 8438 & 9519 & 3661 \\
\hline Iteration & 7 & 8 & 9 & 10 & 11 & 12 \\
\hline GVA & 35185 & -134442 & 778077 & -4130802 & 22276218 & -119778668 \\
\hline
\end{tabular}


As it can be seen, the diagonal elements of the $W$ matrix equals to zero. However this matrix isn't symmetric. The dissymmetry of the $W$ matrix is observed on sensitivity analysis results either (table 4). It is clearly seen, for example, that the impact of education on agriculture is strong, and on the contrary the development of agriculture doesn't impact on education. The symmetry of the matrix had to mean that among all economic activities there are equal direct and inverse relationships. Today the dominant influence of some economic activity sectors on the others without feedback is observed, for example the education affects the agriculture, construction has impact on real estate transactions, public administration affects health care etc. Therefore, as it was proved in the research (Cohen \& Grossberg, 1983), the proposed neural network isn't stable. To check this fact it is enough to make several iterations of correlation (12) and to track the dynamics of GVA, which is calculated as the sum of the elements of the vector:

$$
X^{i+1}=\left(x_{j}\right)^{i+1}, j=\overline{1,9} \quad \text { (table 4). }
$$

As it can be seen on the table, the GVA value was slightly changed on 5 first iterations. These changes are related to calculations rounding errors. Such errors don't lead to strong fluctuations in case of stable neural networks. However starting from the 6-th iteration, a very strong fluctuation, that had disastrous effects, was observed.

Thus, approximating these results on the investigating area, it can be stated, that the selforganizing processes are missed in the system with unequal relationships between economic activities. In other words, after some time the irreversible processes of collapse will be observed in the system left without state governance.

Step 4. The construction of development strategy. To avoid such phenomena it is necessary to develop an effective impact strategy on each model factor for each step of iteration. This can be done by typing additional inputs $\Delta x_{j}$ in neural network (fig. 2). Their semantic content is the external impact of government or investors on $x_{j}$ factors. In fact they reflect the growing of GVA from $j$-th type of economic activity which resulted by effective governance before the next iteration step. Each step of iteration is an analogue to the reporting period and equal to 1 year in this case. Model, presented in a form of Hopfield neural network, allows investigating several possible strategies for managing of the region development. The time period equal to 5 years was investigated as a sample. The 3 strategies are most widespread in this case.

\section{Strategy \#1.}

The development of strategy plan for 5 years with constant stimulation of all types of economic activities. It is necessary to find such impact factors $\Delta X=\left\{\Delta x_{j}\right\}_{j=\overline{1,9}}$, that will be unchanged for 5 years.

Then there is the following task:

$G V A(2015)=G V A^{6}=\sum_{j=1}^{9}\left(x_{j}\right)^{6} \rightarrow \max$

with limitations:

$$
\begin{gathered}
X^{i+1}=\left(X^{i}+\Delta X\right) \cdot W^{T}+B^{T}, i=\overline{1,5} \\
0 \leq \Delta x_{j} \leq p_{j} \cdot\left(x_{j}\right)^{i}, j=\overline{1,9} \\
\left(x_{j}\right)^{i} \geq 0
\end{gathered}
$$

where $p_{j}$ - maximum percentage increase of factor $\left(x_{j}\right)^{i}$.

\section{Strategy \#2.}

The dynamic strategy, which involves the development of a unique optimal strategy for every next year with annual change of impact factors. This leads to an increase of total number of decision variables $\Delta X^{i}=\left\{\Delta x_{j}\right\}_{j=\overline{1,9} ; i=\overline{1,5}}^{i}$. According to dynamic system theory it may lead to better results. To do this it is necessary to solve a separate linear optimization task for each year. The numbers of decision variables for each task are equal to previous case.

$G V A^{i+1}=\sum_{j=1}^{9}\left(x_{j}\right)^{i+1} \rightarrow \max , i=\overline{1,5}$

with limitations:

$$
\begin{gathered}
X^{i+1}=\left(X^{i}+\Delta X^{i}\right) \cdot W^{T}+B^{T}, i=\overline{1,5} \\
0 \leq\left(\Delta x_{j}\right)^{i} \leq\left(p_{j}\right)^{i} \cdot\left(x_{j}\right)^{i}, j=\overline{1,9} \\
\left(x_{j}\right)^{i} \geq 0
\end{gathered}
$$

where $\left(p_{j}\right)^{i}$ maximum percentage increase of factor $\left(x_{j}\right)^{i}$ for $i$-th period . 


\section{Strategy \#3.}

The dynamic strategy of maximization of one goal function for the last $5^{\text {th }}$ year. The number of decision variables of this task is $K=5 \cdot 9=45$ and limitations are analogues to previous case. The goal function looks like in (13). According to dynamic system theory, this strategy must be the most effective (Moore \& Weatherford, 2001).

\section{COMPUTER EXPERIMENT}

As it can be seen from the (13)-(14) equations, each iteration step can appear as a linear programming task. Therefore strategy \#2 is easy to build by using simplex method. The optimization tasks for the first and the third strategies are related to the nonlinear programming because of $X^{i}$ vectors iteration calculation. As our calculations showed, the goal function is nonlinear and consists of local extremes. It makes impossible to use the conjugate gradient method (Maksimov \& Filippovskaya, 1982) because its solution depends on the initial values of decision variables. If the choice is wrong this method finds a local extreme instead of global. Our calculations showed that it's exactly what happens in this case.

Another progressive optimization method is a genetic algorithm. According to it the values of decision variables are the analogue to the genes of living beings. And the goal function determines the adaptation state of living beings with certain genes. The genetic algorithm randomly generates the population of living beings (100 living beings show the population in our calculations). Then the processes of crossing and mutation of these living beings are simulated according to Darwin theory [ (Zhang, Chung, \& Lo, 2007), (Akbari \& Ziarati, 2011)]. The advantage of this method is that the optimization results are not dependent on the initial values of the decision variables. The obtained value is located near the global extreme. The disadvantage is a slow speed of calculations (in our case it takes about 30 minutes for each optimization). The peculiarity of this method is that it allows violating the limitations only slightly.

Therefore the genetic algorithm was used for finding an initial approximation of optimal solutions. After that it was clarified by the classical conjugate gradient method. Calculations were carried out with the approximation that the maximum percentage increase of factor $\left(x_{j}\right)^{i}$ for $i$ th period is $\left(p_{j}\right)^{i}=p_{j}=10 \%$.

The development strategies, obtained as a result of calculations, are presented in the table 5 .

Table 5 The obtained development strategies of region

\begin{tabular}{|c|c|c|c|c|c|c|c|c|c|c|}
\hline & $\Delta x_{1}$ & $\Delta x_{2}$ & $\Delta x_{3}$ & $\Delta x_{4}$ & $\Delta x_{5}$ & $\Delta x_{6}$ & $\Delta x_{7}$ & $\Delta x_{8}$ & $\Delta x_{9}$ & GVA \\
\hline \multicolumn{11}{|c|}{ Strategy \#1 } \\
\hline \multicolumn{11}{|c|}{ Impact factors } \\
\hline & $10 \%$ & $10 \%$ & $10 \%$ & $10 \%$ & $10 \%$ & $10 \%$ & $10 \%$ & $10 \%$ & $8 \%$ & \\
\hline \multicolumn{11}{|c|}{ Gross value added } \\
\hline 2011 & 1980 & 889 & 564 & 1782 & 917 & 567 & 1025 & 1177 & 566 & 9467 \\
\hline 2012 & 1909 & 872 & 570 & 1775 & 903 & 549 & 1026 & 1181 & 569 & 9355 \\
\hline 2013 & 1935 & 940 & 545 & 1850 & 950 & 597 & 1070 & 1159 & 592 & 9637 \\
\hline 2014 & 2116 & 604 & 672 & 1402 & 728 & 392 & 789 & 1281 & 415 & 8398 \\
\hline 2015 & 779 & 2385 & 0 & 3849 & 1888 & 1443 & 2353 & 625 & 1412 & 14735 \\
\hline \multicolumn{11}{|c|}{ Strategy \#2 } \\
\hline \multicolumn{11}{|c|}{ Impact factors } \\
\hline 2011 & $10 \%$ & $10 \%$ & $10 \%$ & $10 \%$ & $10 \%$ & $0 \%$ & $10 \%$ & $9 \%$ & $10 \%$ & \\
\hline 2012 & $10 \%$ & $10 \%$ & $10 \%$ & $10 \%$ & $6 \%$ & $0 \%$ & $10 \%$ & $10 \%$ & $10 \%$ & \\
\hline 2013 & $10 \%$ & $10 \%$ & $10 \%$ & $10 \%$ & $1 \%$ & $0 \%$ & $10 \%$ & $10 \%$ & $10 \%$ & \\
\hline
\end{tabular}




\begin{tabular}{|c|c|c|c|c|c|c|c|c|c|c|}
\hline & $\Delta x_{1}$ & $\Delta x_{2}$ & $\Delta x_{3}$ & $\Delta x_{4}$ & $\Delta x_{5}$ & $\Delta x_{6}$ & $\Delta x_{7}$ & $\Delta x_{8}$ & $\Delta x_{9}$ & GVA \\
\hline 2014 & $7 \%$ & $4 \%$ & $9 \%$ & $10 \%$ & $9 \%$ & $7 \%$ & $9 \%$ & $8 \%$ & $3 \%$ & \\
\hline 2015 & $10 \%$ & $0 \%$ & $10 \%$ & $0 \%$ & $0 \%$ & $0 \%$ & $0 \%$ & $10 \%$ & $0 \%$ & \\
\hline \multicolumn{11}{|c|}{ Gross value added } \\
\hline 2011 & 2014 & 900 & 559 & 1795 & 929 & 537 & 1023 & 1167 & 569 & 9492 \\
\hline 2012 & 2220 & 1006 & 608 & 1999 & 1000 & 567 & 1128 & 1278 & 624 & 10430 \\
\hline 2013 & 2531 & 1149 & 651 & 2237 & 1052 & 628 & 1244 & 1391 & 682 & 11565 \\
\hline 2014 & 2662 & 977 & 793 & 2195 & 998 & 539 & 1202 & 1572 & 626 & 11565 \\
\hline 2015 & 1647 & 2690 & 226 & 4544 & 2119 & 1565 & 2700 & 1097 & 1588 & 18176 \\
\hline \multicolumn{11}{|c|}{ Strategy \#3 } \\
\hline \multicolumn{11}{|c|}{ Impact factors } \\
\hline 2011 & $10 \%$ & $10 \%$ & $9 \%$ & $10 \%$ & $10 \%$ & $3 \%$ & $9 \%$ & $10 \%$ & $8 \%$ & \\
\hline 2012 & $8 \%$ & $9 \%$ & $10 \%$ & $10 \%$ & $3 \%$ & $0 \%$ & $10 \%$ & $10 \%$ & $10 \%$ & \\
\hline 2013 & $10 \%$ & $10 \%$ & $10 \%$ & $10 \%$ & $4 \%$ & $2 \%$ & $9 \%$ & $10 \%$ & $8 \%$ & \\
\hline 2014 & $8 \%$ & $5 \%$ & $10 \%$ & $10 \%$ & $8 \%$ & $6 \%$ & $10 \%$ & $10 \%$ & $6 \%$ & \\
\hline 2015 & $10 \%$ & $0 \%$ & $10 \%$ & $0 \%$ & $0 \%$ & $0 \%$ & $0 \%$ & $10 \%$ & $0 \%$ & \\
\hline \multicolumn{11}{|c|}{ Gross value added } \\
\hline 2011 & 1947 & 904 & 553 & 1811 & 928 & 543 & 1030 & 1171 & 577 & 9463 \\
\hline 2012 & 2290 & 1008 & 600 & 1980 & 984 & 590 & 1105 & 1284 & 606 & 10445 \\
\hline 2013 & 2293 & 1164 & 637 & 2294 & 1054 & 634 & 1278 & 1385 & 719 & 11459 \\
\hline 2014 & 2938 & 908 & 819 & 2040 & 947 & 526 & 1082 & 1643 & 557 & 11459 \\
\hline 2015 & 970 & 3289 & 0 & 5412 & 2483 & 1898 & 3265 & 917 & 1981 & 20216 \\
\hline
\end{tabular}

As it can be seen on the table, compared to trend forecasts $(12,424$ million $\mathrm{UAH}$ and 16,353 million $\mathrm{UAH}$ ), according to the first strategy in 5 years control of the region will be able to get total gross value added for about 14,735 million $\mathrm{UAH}$. It is foreseen by the classical forecasting methods. Instead, the second management strategy will lead to better results $(18,176$ million $\mathrm{UAH})$ than after the optimistic quadratic trend itself. Exceeding of GVA will be $46 \%$ above the linear trend and $11 \%$ over quadratic one. The third strategy appeared to be the most effective. Exceeding of GVA is $63 \%$ and $23 \%$ accordingly. In comparison to the strategy \#2 the goal function increasing is $11 \%$.

Figure 3 presents the comparison of GVA growing dynamics accordingly to 2 trend models and 3 developed strategies. As it can be seen from figures, strategy \#1 isn't effective because during 4 years the GVA value is below the benchmark forecast. For strategies \#2 and \#3 it can be seen that despite the substantial difference of these strategies during the first 4 years their total result was almost identical and was within the linear and quadratic trends. And only for the 5-th year a significant increase in GVA of all three strategies can be observed. Thus strategy planning allows accumulating "internal potential energy" of the system during the first 4 years. This makes it possible to create a stable economic foundation for the further sharp increase in economic performance. Moreover the strategic management for 5 years shows $11 \%$ better results than the annual strategy management. 


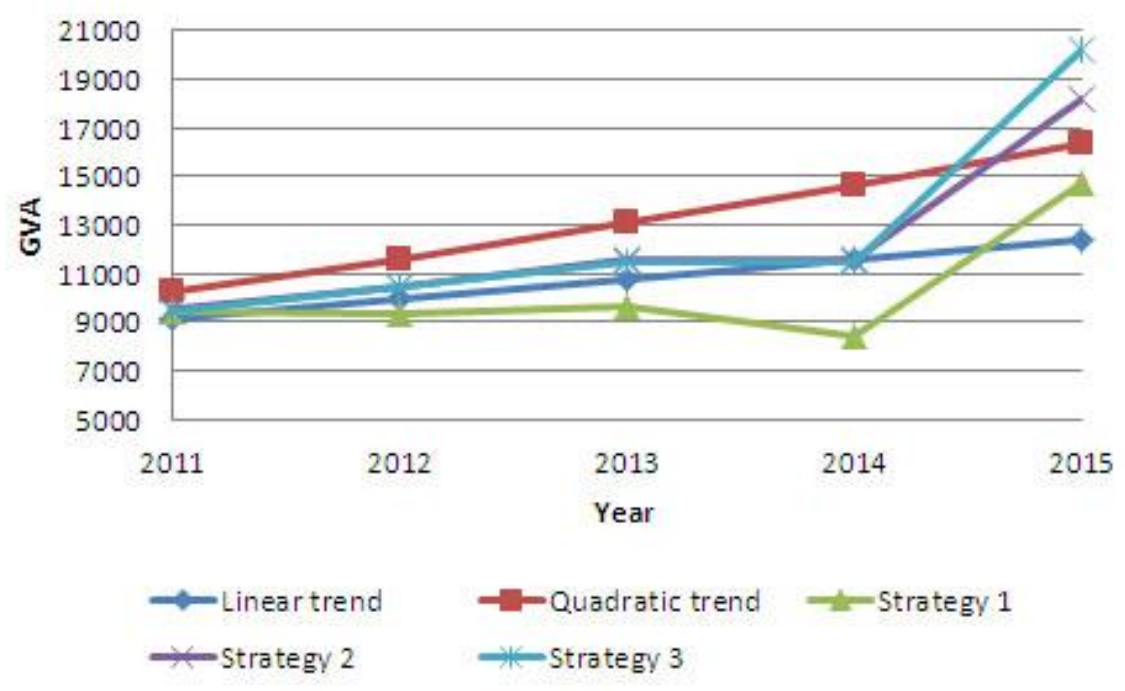

Fig.3 The GVA dynamics according to regional development strategies.

As it is shown in the Table 6, to achieve the maximum effect for the GVA output increase it is necessary to classify them into three groups according to EAK rates and proportions:

Group 1 includes education, construction and agriculture which require a sustained annual dynamic development within the entire billing period.

Group 2 includes trade and repair of motor vehicles, public administration which require a special care as for the development rate during the first four years; manufacturing and healthcare during the first three years. These are specific pulses for the self-development of the system in the future.

Group 3 of EAK includes transport, communications, real estate, leasing, engineering, and providing services to businessmen. This group is not nominating in modeling the development strategy.

\section{CONCLUSIONS}

A new method of modeling a regional strategic management based on the Soft Computing is constructed. Unlike classical approaches, which use mainly an expert analysis, it allows maximizing an economic impact and conduct a quantitative analysis of the proposed strategy.

On the example of the selected region it was proved that the present economic system is not self-organized and it requires an efficient public management. If the regional management strategy is not optimally chosen then in the system some uncontrolled fluctuations can be observed, that may lead to an economic crisis and the "collapse" of the economy system.

Mathematical models of optimization of strategies building of 3 types have been constructed and their effectiveness has been quantitatively researched. It is proved, that the dynamic management strategy with the maximizing of the objective function at the end of the period under investigation, turned out to be the most effective. It is established that public administration which is based on a scientifically grounded quantitative approach, using advanced mathematical models of Soft Computing, allows building a strong economic foundation, which will be the basis for a further rapid growth of the regional economy.

Unlike the current practice it is proposed to complete an expert approach to prioritizing strategies in socio-economic development of regions with some objective quantitative methods.

\section{WORKS CITED}

Akbari, R., \& Ziarati, K. (17 052011 г.). Multi Level Evolutionary Algorithm for Optimizing Numerical Functions, IJIEC, 2, . International Journal of Industrial Engineering Computations, 419-430. doi:10.5267/j.jijiec.2010.03.002 
Atencia, M., Joya, G., \& Sandoval, F. (04 2005 г.). Hopfield Neural Networks for Parametric Identification of Dynamical Systems. Neural Processing Letters, 21(2), 143-152. doi:10.1007/s11063-0043424-3

Cohen, M., \& Grossberg, S. (1983). Absolute Stability of Global Pattern Formation and Parallel Memory Storage by Compatitive Neural Networks. IEEE Transactionson Systems, Manand Cybernetics, 13:8, , 815-826.

Hopfield J.J. (1982). Neural Networks and Physical Systems with Emergent Collective Computational Abilities. Proceedings of the National Academy of Sciences of the USA, 79(8), 2554-2558.

Katsikatsou, M., Moustaki, I., Yang-Wallentin, F., \& Joreskog, K. (12 2012 г.). Pairwise Likelihood Estimation for factor analysis models with ordinal data. Computational Statistics and Data Analysis, 56(12), 4243-4258.

Maksimov, Y. A., \& Filippovskaya, Y. A. (1982). Algoritmy resheniya zadach nelineynogo programmirovaniya. Moskva: MIFI.

Moore, J., \& Weatherford, L. (2001). Decision Modeling with Microsoft Excel. New Jersey: Prentice Hall.

Zhang, J., Chung, H.-H., \& Lo, W.-L. (2007). Clustering-Based Adaptive Crossover and Mutation Probabilities for Genetic Algorithms. IEEE Transactions on Evolutionary Computation, 11(3), 326-335. doi:10.1109/TEVC.2006.880727

Received for publication: $\quad 31.01 .2014$

Revision received: $\quad$ 08.06.2014

Accepted for publication: $\quad 23.06 .2014$

\section{How to cite this article?}

Style - APA Sixth Edition

Vyklyuk, Y., \& Yevdokymenko, V. (2014, 07 15). New methods of soft computing in regional development strategy formation. (Z. Čekerevac, Ed.) MEST Journal, 2(2), 274-284. doi:10.12709/mest.02.02.02.28

Style - Chicago Fifteenth Edition:

Vyklyuk, Yaroslav, and Valeriy Yevdokymenko. 2014. "New methods of soft computing in regional development strategy formation." Edited by Zoran Čekerevac. MEST Journal (MESTE) 2 (2): 274-284. doi:10.12709/mest.02.02.02.28.

\section{Style - GOST Name Sort:}

Vyklyuk Yaroslav and Yevdokymenko Valeriy New methods of soft computing in regional development strategy formation [Journal] // MEST Journal / ed. Čekerevac Zoran. - Belgrade : MESTE, 07 15, 2014. - 2 : Vol. 2. - pp. 274-284.

\section{Style - Harvard Anglia:}

Vyklyuk, Y. \& Yevdokymenko, V., 2014. New methods of soft computing in regional development strategy formation. MEST Journal, 15 07, 2(2), pp. 274-284.

Style - ISO 690 Numerical Reference:

New methods of soft computing in regional development strategy formation. Vyklyuk, Yaroslav and Yevdokymenko, Valeriy. [ed.] Zoran Čekerevac. 2, Belgrade : MESTE, 07 15, 2014, MEST Journal, Vol. 2, pp. 274-284. 